(6) OPEN ACCESS

\title{
Is it time to reassess current safety standards for glyphosate-based herbicides?
}

Laura N Vandenberg, ${ }_{1}^{1}$ Bruce Blumberg, ${ }^{2}$ Michael N Antoniou, ${ }^{3}$ Charles M Benbrook, ${ }^{4,5}$ Lynn Carroll, ${ }^{6}$ Theo Colborn, ${ }^{6, ₹}$ Lorne G Everett, $^{7}$ Michael Hansen, ${ }^{8}$ Philip J Landrigan, ${ }^{9}$ Bruce P Lanphear, ${ }^{10}$ Robin Mesnage, ${ }^{3}$ Frederick S vom Saal, ${ }^{11}$ Wade V Welshons, ${ }^{12}$ John Peterson Myers ${ }^{13,14}$

For numbered affiliations see end of article.

\section{Correspondence to} Dr Laura N Vandenberg, Department of Environmental Health Sciences, University of Massachusetts-Amherst, 171A Goessmann, 686 N. Pleasant Street, Amherst, MA 01003, USA; Ivandenberg@schoolph. umass.edu

$¥ D r$ Colborn's contributions to this project were made prior to her passing in late 2014. All authors agreed that she should remain an author on this manuscript. Moreover, the authors express their gratitude to her dedication to this project, and other work that advanced the field of environmental health.

Received 24 November 2016 Revised 25 January 2017 Accepted 30 January 2017 Published Online First 22 February 2017
CrossMark

To cite: Vandenberg LN, Blumberg B, Antoniou MN, et al. J Epidemiol Community Health 2017;71:613-618.

\section{ABSTRACT}

Use of glyphosate-based herbicides (GBHs) increased 100-fold from 1974 to 2014. Additional increases are expected due to widespread emergence of glyphosateresistant weeds, increased application of GBHs, and preharvest uses of GBHs as desiccants. Current safety assessments rely heavily on studies conducted over 30 years ago. We have considered information on GBH use, exposures, mechanisms of action, toxicity and epidemiology. Human exposures to glyphosate are rising, and a number of in vitro and in vivo studies challenge the basis for the current safety assessment of glyphosate and GBHs. We conclude that current safety standards for GBHs are outdated and may fail to protect public health or the environment. To improve safety standards, the following are urgently needed: (1) human biomonitoring for glyphosate and its metabolites; (2) prioritisation of glyphosate and GBHs for hazard assessments, including toxicological studies that use state-of-the-art approaches; (3) epidemiological studies, especially of occupationally exposed agricultural workers, pregnant women and their children and (4) evaluations of GBHs in commercially used formulations, recognising that herbicide mixtures likely have effects that are not predicted by studying glyphosate alone.

\section{INTRODUCTION}

Glyphosate is an active ingredient in a number of commercially available herbicides, including several that are used in concert with genetically modified crops. The herbicidal action of glyphosate derives from its inhibition of a key plant enzyme, 5-enolpyruvylshikimate-3-phosphate synthase, which is involved in the synthesis of aromatic amino acids. Since this enzyme is not present in vertebrates, it has long been believed that glyphosate would not affect non-target species, including humans. However, multiple lines of evidence suggest that this contention is inaccurate.

Methods used in environmental health sciences to examine the potential health effects of chemicals, including pesticides, have undergone substantial changes over the past 30 years. Cutting-edge tools currently employed by federally funded scientists bear little resemblance to the archaic standardised assays required by regulatory agencies and used in formal risk assessments. ${ }^{1}$ We are concerned that the assays used to assess glyphosate safety, including the toxicity studies requested by the US Environmental Protection Agency (EPA) in 2009, may be insufficient to address the full complement of health effects that could be induced by exposure to glyphosate-based herbicides (GBHs).

In this commentary, we summarise these key findings as well as trends in increased use of GBHs. Since commercial applications of GBHs began four decades ago, their use has diversified and expanded considerably. We offer recommendations on how to reduce significant uncertainties concerning $\mathrm{GBH}$ risks.

\section{GLYPHOSATE USE HAS INCREASED SINCE SAFETY EVALUATIONS WERE CONDUCTED}

Glyphosate was registered in 1974 in the USA as a broad-spectrum contact herbicide to kill weeds in fields prior to the planting of crops. It was also approved for weed control in a variety of non-crop settings. Glyphosate use is the highest of any pesticide in the USA, with rapid increases in use over the last two decades; worldwide estimates of use suggest that enough GBH was applied in 2014 to spray nearly $0.5 \mathrm{~kg}$ glyphosate on every hectare of cropland on the planet. ${ }^{2}$

In addition to their use as weed-control herbicides, GBHs are now used as desiccants prior to harvest ${ }^{3}$ to accelerate natural drying of seeds. These use patterns are expected to increase glyphosate residue levels in harvested products. Although such effects still need to be evaluated in controlled studies, residues of glyphosate and aminomethylphosphonic acid (AMPA) (the major bioactive metabolite of glyphosate) are now routinely detected in soybeans, wheat, barley, and many other crops and foods. ${ }^{45}$

Although GBH use has increased dramatically in the last 10 years, most of the science used in the risk assessment process to support its safety was conducted more than 30 years ago. In the US EPA's 1993 registration review of GBHs, ${ }^{6}$ for example, $73 \%$ of the almost 300 citations were published prior to 1985 ; importantly, only 11 were peerreviewed. A search of PubMed (conducted 6 November 2016) reveals more than 1500 published studies on glyphosate in the last decade alone. It is incongruous that safety assessments of the most widely used herbicide on the planet rely largely on fewer than 300 unpublished, non-peer-reviewed studies while excluding the vast, modern literature on glyphosate effects.

Considering the $\sim 100$-fold increase in GBH use in the last four decades, increased human exposure is almost certain. Unfortunately, no systematic data have tracked changes in glyphosate or AMPA concentrations in human tissues or bodily fluids during 
this period. For this reason, we recommend that glyphosate and AMPA should be monitored by the US Centers for Disease Control and Prevention (US CDC) in its National Health and Nutrition Examination Survey (NHANES) biomonitoring programme, as well as other biomonitoring programmes around the world. Studies of the general population to evaluate actual exposures via diet (rather than hypothetical inferred exposures), as well as studies in occupationally exposed individuals (eg, pesticide sprayers as well as production workers), are both needed.

\section{ARE HUMANS AFFECTED BY GBHS?}

There are few human epidemiology studies examining the impact of glyphosate on human diseases. Unexplained chronic kidney disease has killed thousands of rice farm workers in Sri Lanka $^{7}$ and sugarcane workers in Central America; ${ }^{8}$ exposure to herbicides including GBHs has been documented in some of these populations. 9 Some epidemiologists have hypothesised that epidemics of chronic kidney disease among male agricultural workers result from the interactions of the herbicide with hard drinking water and associated metals. ${ }^{7}$ Others have attributed these health conditions to dehydration. ${ }^{10}$ Neither explanation is plausible because such plantation work in these regions has been going on for centuries while the epidemic of kidney failure and herbicide use are recent phenomena.

A number of other studies have evaluated the association between exposures to GBHs and other health effects in humans including cancer. In fact, some of the most compelling studies in human populations suggest associations between GBHs and non-Hodgkin lymphoma. ${ }^{11}{ }^{12}$ Cancer end points will be discussed later in this commentary.

Without appropriate epidemiological and biomonitoring studies, any association between glyphosate and AMPA concentrations found in human tissues and fluids with disease will remain uncertain. Epidemiological studies are urgently needed to augment the ability of risk assessors to draw better conclusions about the safety of GBHs. Such studies should evaluate short-term and long-term health outcomes including DNA damage and cancer.

\section{RECENT STUDIES RAISE NEW QUESTIONS ABOUT GBH SAFETY}

In laboratory animals, glyphosate can disrupt reproductive development in male rats, ${ }^{13}$ and male and female fish. ${ }^{14}{ }^{15}$ Studies in fish and the amphibian Xenopus laevis demonstrate that developmental exposures to GBHs induce malformations in craniofacial structures and the brain, although the mechanism underlying these effects is not fully understood. ${ }^{16}{ }^{17}$ Research from controlled laboratory studies also suggests that GBHs may contribute to liver, ${ }^{18}$ hepatorenal ${ }^{19-22}$ and cardiovascular damage; ${ }^{23}{ }^{24}$ some of these effects may be due to altered ion flux in these tissues. ${ }^{25}$ GBHs are also recognised to cause serious eye damage based on evaluation of six separate studies. $^{26}$ Finally, GBH exposures have been shown to induce oxidative stress $^{27}$ and genotoxicity ${ }^{28}$ in vitro and in vivo.

In a previous consensus statement, we analysed these data and raised concerns over the setting of 'safe' levels of exposure by regulatory agencies around the world; ${ }^{29}$ other comprehensive reviews of the toxicity literature also provide an excellent overview of the effects of glyphosate and GBHs on a range of end points. 3031

Recently, there has been debate over the possibility that glyphosate is an endocrine disruptor. ${ }^{13}{ }^{14}{ }^{32-34}$ Studies in cell culture showed that glyphosate induces endocrine-mediated effects on end points relevant to toxicity, as well as cell proliferation. $^{32} 33$ In contrast, using their Endocrine Disruptor Screening Program (EDSP), the US EPA's recent review of glyphosate dismissed statistically significant differences consistent with oestrogenic activity in some assays (eg, altered vitellogenin levels in a fish short-term reproduction assay) because they followed a non-monotonic dose response. ${ }^{35}$ The final conclusion of the US EPA was that 'there was no convincing evidence' that glyphosate interacts with endocrine pathways. Significant criticisms of the EDSP assays have been raised by endocrinologists, and others have expressed concern about the failure of the EPA to acknowledge non-monotonic dose responses, which have been documented for other endocrine disruptors. ${ }^{36}$ Other agencies including the European Food Safety Authority (EFSA) have used the EDSP data to suggest that there is not sufficient evidence to conclude that glyphosate is an endocrine disruptor, but the 2015 EFSA report does note that 'signs of endocrine activity... could not be completely ruled out' in some of these assays. $^{37}$

In December 2009, the US EPA issued a 'Glyphosate Final Work Plan (FWP) registration review' ${ }^{38}$ that identified uncertainties about the toxicity of glyphosate. For example, the EPA announced its plan to require that registrants conduct acute and subchronic neurotoxicity studies as well as an immunotoxicity study. The EPA also acknowledged that AMPA had not been evaluated for ecological risk assessments. Since this testing is supposed to be conducted by the registrants, it is unclear whether testing is underway, will actually be completed, or will be published in the peer-reviewed literature. Thus, additional studies, using state-of-the-art approaches, are needed to better elucidate the effects of glyphosate and GBHs on non-target species. We recommend that scientists and entities independent of the registrants, (eg, the US National Toxicology Program (NTP)) should prioritise glyphosate and GBHs for hazard assessments. In fact, the US EPA also proposed a collaborative research plan with the NTP, which calls for NTP to help provide answers to four research questions: (1) comparisons of the toxicity of glyphosate versus GBH formulations; (2) provide publicly available data on glyphosate's effects on cancer-related end points; and (3) non-cancer end points; (4) finally, investigate the mechanisms by which glyphosate and GBHs induce toxic and adverse effects. ${ }^{39}$ Several of these points are addressed further below.

\section{GBHS ARE CHEMICAL MIXTURES, AND MAY BE MORE TOXIC THAN GLYPHOSATE ALONE}

GBHs are always used as a mixture of glyphosate plus numerous other so called inert ingredients, which are added to alter the herbicide's physicochemical properties and enhance its herbicidal action. Some inert ingredients or chemicals are used to enhance the adhesion of glyphosate to plant surfaces (eg, alkyl polyglycosides), whereas others facilitate its penetration of plant cell walls and into plant tissues (eg, ethoxylated tallow amines) to exert its herbicidal effects. Unfortunately, the full list of these chemicals, collectively known as adjuvants or coformulants, is treated as a trade secret by the manufacturers; the composition of GBHs are unknown and available data on the hazards posed by different mixtures remain limited.

Chemical mixtures can have effects that are more potent than the effects of individual ingredients. ${ }^{40} \mathrm{GBH}$ s have been shown to be more toxic than glyphosate. ${ }^{41-44}$ It also should be noted that some of the studies discussed in the previous section of this review evaluated GBHs, and thus likely reveal effects that may not be observed if studies examined only the active ingredient. 
These results reveal that GBH safety evaluations focused on glyphosate alone can underestimate toxicity and are insufficient to assess relevance to human and environmental exposures. Although the number of commercial formulations is extensive and will be difficult to study comprehensively, we propose that the most widely applied GBH formulations should be tested in parallel with glyphosate alone.

\section{IS GLYPHOSATE A HUMAN CARCINOGEN?}

Over the last few years, glyphosate has received significant attention by the public as well as regulatory agencies around the world. In the European Union, safety evaluations on glyphosate have recently been conducted by the European Chemicals Agency (ECHA) and EFSA; in the USA, meetings by evaluation committees within the US EPA scheduled for fall 2016 were cancelled so the agency could supplement the panel of experts with additional members who have expertise in epidemiology. In December 2016, an EPA scientific advisory panel was charged with evaluating the human carcinogenic potential of glyphosate only, not GBHs. The conclusions of this panel have not yet been released.

The WHO's International Agency for Research on Cancer (IARC) working group's 2015 decision to classify glyphosate as a grade $2 \mathrm{~A}$ probable human carcinogen followed an extensive review and evaluation of the weight of all available evidence. ${ }^{45}$ The outcome was driven by: (1) limited human evidence from case-control epidemiology studies, including high-quality studies reporting a link with non-Hodgkin lymphoma; ${ }^{11}{ }^{12}$ (2) sufficient evidence from unpublished animal studies analysed by the US EPA, which identified an elevated frequency of rare kidney tumours in male mice, hemangiosarcoma in male mice, pancreatic islet-cell adenoma in male rats, and skin tumours and other non-malignant growths in mice and (3) strong mechanistic evidence, such as numerous studies demonstrating that glyphosate is genotoxic and can induce oxidative stress in humans, human cells, non-human mammals and non-mammalian species (data reviewed in depth in ref. 46). Other data from unpublished studies that have been reviewed in the peer-reviewed literature could not be evaluated by IARC because the data were not publicly available; some of these studies also suggest increases in lymphoma in male mice exposed even to the lowest doses evaluated $(14.5 \mathrm{mg} / \mathrm{kg} /$ day) (see study 13 evaluated in ref. 47).

A joint meeting on pesticides residues (JMPR) in the WHO used the IARC hazard assessment evaluation (eg, concluding that glyphosate is a probable human carcinogen) to establish a safe level of exposure for humans. In their most recent evaluation, JMPR would not exclude the possibility that glyphosate is a human carcinogen, but concluded that it 'is unlikely to pose a carcinogenic risk to humans from exposure through the diet'. ${ }^{48}$ The JMPR did not conduct a quantitative assessment to estimate cancer risk at current dietary exposures, and, more crucially, did not evaluate actual dietary exposures in any population.

The IARC classification was made based on an analysis of the entire body of evidence, including the evaluation of GBH (mixtures) and not glyphosate alone, as IARC requires that 'the body of evidence is considered as a whole.... ${ }^{49}$ A 2016 review of the carcinogenic potential of glyphosate by EFSA contrasts with the IARC conclusions. $^{37}$ EFSA concluded that 'glyphosate is unlikely to pose a carcinogenic hazard to humans' but notes that it drew its conclusions based only on studies of glyphosate alone; studies of GBHs were not included in the EFSA assessment. Other agencies in the European Union, including the German Federal Institute for Risk Assessment, have similarly focused on studies of the active ingredient, failing to consider all studies of GBHs. ${ }^{50}$ Furthermore, the EFSA monograph notes that studies that demonstrate the genotoxicity of glyphosate that were considered by IARC were not considered by EFSA because they did not follow prescribed guidelines for study reporting (eg, good laboratory practices, or GLP); ${ }^{37}$ this argument has also been made to eliminate studies conducted within academia in other risk assessments, ${ }^{1}$ despite evidence that academic laboratory research can be well designed and properly reported in the absence of GLP. ${ }^{51}$ Importantly, studies conducted according to GLP (including study 13 evaluated in ref. 47) that suggest causal links between glyphosate and cancer in exposed rodents have been dismissed by agencies including the EPA and EFSA due to speculation about a viral infection in the animal colony, even though no adverse health effects of such an infection have been shown. ${ }^{26}$

After the release of the IARC and EFSA expert conclusions, there were a number of public discussions and articles written for lay audiences describing how these organisations could come to conflicting results after reviewing the same literature. These discussions revealed that the same literature often was not evaluated: IARC examined studies of $\mathrm{GBH}$ and glyphosate whereas EFSA only evaluated studies of glyphosate; IARC examined all studies whereas EFSA gave priority to studies conducted according to GLP. Finally, IARC has strict conflict of interest rules about the experts that serve on its panels, whereas other agencies including EFSA do not exclude experts that have received monetary compensation from chemical manufacturers. There is evidence that the presence of individuals with conflicts of interest on regulatory panels can influence the integrity of decision making. ${ }^{52} 53$

\section{WHERE DOES THE BURDEN OF PROOF OF SAFETY LIE?}

The EFSA report, evaluating only studies of glyphosate and not $\mathrm{GBH}$ mixtures, concluded that there was no evidence to conclude that it is a carcinogen. ${ }^{37}$ The European Commission has not yet accepted the EFSA conclusion; in 2016, because European Union member states failed to take action against glyphosate, the European Commission extended its approval for its use under certain circumstances for 18 months, giving ECHA this time to review glyphosate's classification. In the interim, the Commission recommended that an adjuvant, ethoxylated tallow amine, be banned from GBHs; that spraying of public parks, playgrounds and gardens be minimised; and that preharvest uses be minimised. ${ }^{54}$ It will be up to the individual member states to approve and enforce these recommendations.

In the USA, the Federal Insecticide, Fungicide, and Rodenticide Act (FIFRA, (7 U.S.C. $\$ 136$ et seq. (1996))) requires chemical manufacturers to demonstrate that a pesticide will not cause 'unreasonable adverse effects on the environment'. Although FIFRA allows risks to humans and the environment to be balanced by the benefits of a pesticide's use, this can only be accomplished if sufficient data are available to support safety. It also can only be accomplished if the full costs of exposure, including costs to human health, are quantified (see ref. ${ }^{55}$ for a discussion of the costs of other environmental chemicals).

FIFRA places the burden to demonstrate that a pesticide is safe on the manufacturers and registrants. Yet the knowledge gaps that currently exist preclude the drawing of conclusions that GBHs are safe as currently used. FIFRA provides the US EPA with the means to restrict the use of pesticides, to update registered pesticides (like glyphosate) with new safety information, and to take action when new evidence of adverse environmental or human health effects are reported (7 U.S.C. $\$ 136$ et 
seq. (1996)). The studies we have outlined in this commentary, together with the burden of proof for safety on the chemical manufacturer, clearly suggests that such actions are needed.

\section{CONCLUSIONS}

In this commentary, we have identified factors that heighten concerns over the adequacy of safety assessments, and by extension, permitted levels of exposure to glyphosate and GBHs. These factors include increased use of GBHs on crops and for non-crop weed control, leading to measurable concentrations of glyphosate and AMPA in foodstuffs and likely increases in human exposures. The lack of biomonitoring data and epidemiological studies remain important data gaps. A small number of controlled laboratory studies using contemporary scientific approaches have identified adverse effects of glyphosate and GBHs at much lower doses than those used to make risk assessment decisions. Although there is controversy and debate regarding the carcinogenic and endocrine disrupting potential of these compounds, conclusions such as those drawn by IARC call into question the safety of GBHs beyond 'reasonable certainty of no harm'. Considering what is now known about glyphosate from studies published over the last three decades, as well as the knowledge gaps that continue to raise concerns, we conclude that current safety standards for GBHs are outdated and may fail to protect public health and the environment.

\section{What is already known}

- Glyphosate is a widely used herbicide, and its use continues to rise

- Epidemiology studies suggest associations between GBH exposures and adverse health outcomes including chronic kidney disease and some cancers

- A small number of rodent studies suggest that glyphosate can induce cancers

- The effects of chemical mixtures can be more toxic than the effects of individual compounds

\section{What this study adds}

- We call for improved biomonitoring of glyphosate and its metabolites in human populations

- We recommend that hazard assessments using state-of-theart technical approaches be conducted on glyphosate and GBHs

- Epidemiological studies examining occupationally exposed workers, pesticide manufacturers, and vulnerable populations are needed

- After review of all evaluations, we conclude that the current safety standards are outdated and fail to protect public health and the environment.

\section{Author affiliations}

${ }^{1}$ Department of Environmental Health Sciences, School of Public Health and Health Sciences, University of Massachusetts-Amherst, Amherst, Massachusetts, USA ${ }^{2}$ Department of Developmental and Cell Biology, University of California, Irvine, California, USA

${ }^{3}$ Department of Medical and Molecular Genetics, Faculty of Life Sciences and
}

Medicine, King's College London, London, UK

${ }^{4}$ University of Newcastle, Newcastle, UK

${ }^{5}$ Benbrook Consulting Services, Enterprise, Oregon, USA

${ }^{6}$ TEDX, The Endocrine Disruption Exchange, Paonia, Colorado, USA

${ }^{7}$ L. Everett \& Associates, Santa Barbara, California, USA

${ }^{8}$ Consumers Union, Yonkers, New York, USA

${ }^{9}$ Department of Preventive Medicine, Icahn School of Medicine at Mount Sinai, New York, New York, USA

${ }^{10}$ Child \& Family Research Institute, BC Children's Hospital, University of British Columbia, Vancouver, British Columbia, Canada

${ }^{11}$ Division of Biological Sciences, University of Missouri, Columbia, Missouri, USA

${ }^{12}$ Department of Biomedical Sciences, University of Missouri-Columbia, Columbia, Missouri, USA

${ }^{13}$ Environmental Health Sciences, Charlottesville, Virginia, USA

${ }^{14}$ Carnegie Mellon University, Pittsburgh, Pennsylvania, USA

Acknowledgements The authors gratefully acknowledge support from the World Federation of Scientists, which funded travel for many of the authors to attend the 48th Session of the International Seminars on Planetary Emergencies and Associated Events, where work on this manuscript was conducted.

Contributors All authors participated in conference calls and group discussions about this topic. LNV wrote the first draft. Additional text was contributed by BB. All authors reviewed, edited and agreed to publish this manuscript.

Funding Wallace Genetic Foundation; Marisla Foundation; World Federation of Scientists; Broad Reach Fund.

Competing interests LNV has received grants from the National Institutes of Health and funding from the Cornell Douglas foundation. She has been reimbursed for travel expenses by numerous organisations including SweTox, Israel Environment Fund, the Mexican Endocrine Society, Advancing Green Chemistry, ShiftCon, US EPA, Croplife America, BeautyCounter, and many universities, to speak about endocrine disrupting chemicals. She received payment as an expert witness in a case about a commercial plastic with suspected endocrine disrupting properties. MNA receives support from the Sustainable Food Alliance, Breast Cancer UK, The Sheepdrove Trust (UK) and the Safe Food Institute (Australia). CMB is principal of Benbrook Consulting Services, Enterprise, OR. He received support in a grant to Washington State University from the Ceres Trust. BB is a named inventor on several patents related to nuclear receptor function and testing (US 5861 274; 6200 802; 6815 168; 6274 321; 6391847 ; 6756 491; 6809 178; 6984 773), some of which generate royalty income. He has received grant support from the U.S. National Institutes of Health, National Science Foundation, American Heart Association, State of California, and the Swedish Environmental Agency FORMAS. He receives occasional research gifts from Advancing Green Chemistry and occasional travel awards from professional societies and non-profit organizations in the US and elsewhere. None of these constitutes an actual, or perceived conflict of interest. LC and TC are employed by TEDX, The Endocrine Disruption Exchange, Paonia, CO. Contributions by Lynn Carroll and Theo Colborn were supported entirely by grants to TEDX from the Winslow Foundation and the Wallace Genetic Foundation. LGE is principle of $L$. Everett and Associates, Santa Barbara, CA. MH is employed by the Consumers Union, Yonkers, NY. BPL served as an expert witness in California for the plaintiffs in a public nuisance case of childhood lead poisoning, a Proposition 65 case on behalf of the California Attorney General's Office, a case involving lead-contaminated water in a new housing development in Maryland, and Canadian tribunal on trade dispute about using lead-free galvanised wire in stucco lathing but he received no personal compensation for these services. He is currently representing the government of Peru as an expert witness in a suit involving Doe Run versus Peru, but he is receiving no personal compensation. BPL has served as a paid consultant on a US Environmental Protection Agency research study, NIH research awards and the California Department of Toxic Substance Control. BPL has received federal research awards from the National Institute of Environmental Health Sciences, the US Environmental Protection Agency, the Centers for Disease Control and the US Department of Housing and Urban Development. He is also the recipient of federal research awards from the Canada Institutes of Health Research and Health Canada. FSvS has received grants from the National Institutes of Health, National Science Foundation, National Institute of Mental Health, US Department of Agriculture, US Geological Survey, Environmental Protection Agency, Food and Drug Administration, Purina-Mills Corporation, Environmental Health Sciences, John Merck Fund, Johnson Family foundation, Mitchell Kapor Foundation, Passport Foundation, Weldon Springs Foundation and W. Alton Jones Foundation; he has received payment for consulting on a number of cases involving bisphenol $A$ and has received cash awards from the Heinz Family Foundation and Jenifer Altman Foundation as well as honoraria to speak at numerous scientific conferences and universities. WVW received support from the Jenifer Altman Foundation. JPM is employed by Environmental Health Sciences, Charlottesville, VA. He received support from the Broad Reach Fund, the Marisla Foundation and the Wallace Genetic Foundation for this work.

Provenance and peer review Commissioned; externally peer reviewed. 
Open Access This is an Open Access article distributed in accordance with the Creative Commons Attribution Non Commercial (CC BY-NC 4.0) license, which permits others to distribute, remix, adapt, build upon this work non-commercially, and license their derivative works on different terms, provided the original work is properly cited and the use is non-commercial. See: http://creativecommons.org/ licenses/by-nc/4.0/

\section{REFERENCES}

1 Myers JP, vom Saal FS, Akingbemi BT, et al. Why public health agencies cannot depend on good laboratory practices as a criterion for selecting data: the case of bisphenol A. Environ Health Perspect 2009;117:309-15.

2 Benbrook CM. Trends in glyphosate herbicide use in the United States and globally. Environ Sci Eur 2016;28:3.

3 Monsanto International sarl, Monsanto Europe SA. The agronomic benefits of glyphosate in Europe: review of the benefits of glyphosate per market use. http://www.monsanto.com/products/documents/ glyphosate-background-materials/agronomic $\% 20$ benefits $\% 20$ of $\% 20$ glyphosate \%20in\%20europe.pdf, 2010:1-82.

4 Bøhn T, Cuhra M, Traavik T, et al. Compositional differences in soybeans on the market: glyphosate accumulates in roundup ready GM soybeans. Food Chem 2014;153:207-15.

5 National Agricultural Statistics Service. NASS releases 2012 chemical use data for soybeans and wheat. In: agricultural statistics Board, ed. 2013. http://usda. mannlib.cornell.edu/usda/current/AgriChemUsFC/AgriChemUsFC-05-15-2013. txt.

6 US EPA. Reregistration Eligibility Decision: Glyphosate. EPA 738-R-93-014. 1993.

7 Jayasumana C, Gunatilake S, Senanayake P. Glyphosate, hard water and nephrotoxic metals: are they the culprits behind the epidemic of chronic kidney disease of unknown etiology in Sri Lanka? Int I Environ Res Public Health 2014:11:2125-47.

8 Peraza S, Wesseling C, Aragon A, et al. Decreased kidney function among agricultural workers in El Salvador. Am J Kidney Dis 2012;59:531-40.

9 Jayasumana C, Paranagama P, Agampodi S, et al. Drinking well water and occupational exposure to hierbicides is associated with chronic kidney disease, in Padavi-Sripura, Sri Lanka. Environ Health 2015;14:6.

10 Crowe J, Wesseling $C$, Solano BR, et al. Heat exposure in sugarcane harvesters in Costa Rica. Am J Ind Med 2013:56:1157-64.

11 Eriksson M, Hardell L, Carlberg M, et al. Pesticide exposure as risk factor for non-Hodgkin lymphoma including histopathological subgroup analysis. Int I Cancer 2008:123:1657-63.

12 De Roos AJ, Zahm SH, Cantor KP, et al. Integrative assessment of multiple pesticides as risk factors for non-Hodgkin's lymphoma among men. Occup Environ Med 2003:60:E11.

13 Romano MA, Romano RM, Santos LD, et al. Glyphosate impairs male offspring reproductive development by disrupting gonadotropin expression. Arch Toxicol 2012:86:663-73.

14 Armiliato N, Ammar D, Nezzi L, et al. Changes in ultrastructure and expression of steroidogenic factor-1 in ovaries of zebrafish Danio rerio exposed to glyphosate. $J$ Toxicol Environ Health Part A 2014;77:405-14.

15 Lopes FM, Varela Junior AS, Corcini CD, et al. Effect of glyphosate on the sperm quality of zebrafish Danio rerio. Aquat Toxicol 2014;155:322-6.

16 Paganelli A, Gnazzo V, Acosta H, et al. Glyphosate-based herbicides produce teratogenic effects on vertebrates by impairing retinoic acid signaling. Chem Res Toxicol 2010;23:1586-95.

17 Roy NM, Carneiro B, Ochs J. Glyphosate induces neurotoxicity in zebrafish. Environ Toxicol Pharmacol 2016;42:45-54.

18 Mesnage R, Renney G, Séralini GE, et al. Multiomics reveal non-alcoholic fatty liver disease in rats following chronic exposure to an ultra-low dose of Roundup herbicide. Sci Rep 2017;7:39328.

19 Séralini GE, Clair E, Mesnage R, et al. Republished study: long-term toxicity of a Roundup herbicide and a Roundup-tolerant genetically modified maize. Environ Sci Eur 2014;26:14.

20 Benedetti AL, Vituri Cde L, Trentin AG, et al. The effects of sub-chronic exposure of Wistar rats to the herbicide Glyphosate-Biocarb. Toxicol Lett 2004;153: 227-32.

21 Mesnage R, Arno M, Costanzo M, et al. Transcriptome profile analysis reflects rat liver and kidney damage following chronic ultra-low dose Roundup exposure. Environ Health 2015;14:70.

22 Uren Webster TM, Santos EM. Global transcriptomic profiling demonstrates induction of oxidative stress and of compensatory cellular stress responses in brown trout exposed to glyphosate and Roundup. BMC Genomics 2015;16:32.

23 Roy NM, Ochs J, Zambrzycka E, et al. Glyphosate induces cardiovascular toxicity in Danio rerio. Environ Toxicol Pharmacol 2016;46:292-300.

24 Gress S, Lemoine S, Séralini GE, et al. Glyphosate-based herbicides potently affect cardiovascular system in mammals: review of the literature. Cardiovasc Toxicol 2015;15:117-26.
25 Gress S, Lemoine S, Puddu PE, et al. Cardiotoxic electrophysiological effects of the herbicide roundup((R)) in rat and rabbit ventricular myocardium in vitro. Cardiovasc Toxicol 2015;15:324-35.

26 BAuA Federal Institute for Occupational Safety and Health. Proposal for harmonized classification and labelling. Substance name: $\mathrm{N}$-(phosphonomethyl)glycine; Glyphosate (ISO). In: EChA, ed. 2016. https://www.echa.europa.eu/documents/ 10162/13626/clh_report_glyphosate_en.pdf.

27 Larsen $\mathrm{K}$, Najle R, Lifschitz A, et al. Effects of sub-lethal exposure of rats to the herbicide glyphosate in drinking water: glutathione transferase enzyme activities, levels of reduced glutathione and lipid peroxidation in liver, kidneys and small intestine. Environ Toxicol Pharmacol 2012;34:811-18.

28 Alvarez-Moya C, Silva MR, Ramírez CV, et al. Comparison of the in vivo and in vitro genotoxicity of glyphosate isopropylamine salt in three different organisms. Genet Mol Biol 2014;37:105-10

29 Myers JP, Antoniou MN, Blumberg B, et al. Concerns over use of glyphosate-based herbicides and risks associated with exposures: a consensus statement. Environ Health 2015:15:19.

30 Mesnage R, Defarge N, Spiroux de Vendômois J, et al. Potential toxic effects of glyphosate and its commercial formulations below regulatory limits. Food Chem Toxicol 2015;84:133-53.

31 Antoniou M, Habib MEM, Howard CV, et al. Teratogenic effects of glyphosate-based herbicides: divergence of regulatory decisions from scientific evidence. J Environ Anal Toxicol 2012;S4:006.

32 Thongprakaisang S, Thiantanawat A, Rangkadilok N, et al. Glyphosate induces human breast cancer cells growth via estrogen receptors. Food Chem Toxicol 2013;59:129-36.

33 Gasnier C, Dumont C, Benachour N, et al. Glyphosate-based herbicides are toxic and endocrine disruptors in human cell lines. Toxicology 2009;262:184-91.

34 Walsh LP, McCormick C, Martin C, et al. Roundup inhibits steroidogenesis by disrupting steroidogenic acute regulatory (StAR) protein expression. Environ Health Perspect 2000;108:769-76.

35 US EPA. Chemical: Glyphosate. EDSP: weight of evidence analysis of potential interaction with the estrogen, androgen or thyroid pathways. 2015. http://www.epa. gov/sites/production/files/2015-06/documents/glyphosate-417300_2015-06-29_ txr0057175.pdf

36 Vandenberg LN, Colborn T, Hayes TB, et al. Hormones and endocrine-disrupting chemicals: low-dose effects and nonmonotonic dose responses. Endocr Rev 2012;33:378-455.

37 EFSA. Conclusion on the peer review of the pesticide risk assessment of the active substance glyphosate. EFSA J 2015;13:4302

38 US EPA. Glyphosate Summary Document Registration Review: Initial Docket. Doc. Number EPA-HQ-OPP-2009-0361. 2009. http://www.regulations.gov/\#! documentDetail; D=EPA-HQ-OPP-2009-0361-0002.

39 US EPA. Glyphosate issue paper: evaluation of carcinogenic potential. In: EPA's Office of Pesticide Programs, ed. 2016. https://www.epa.gov/sites/production/files/ 2016-09/documents/glyphosate_issue_paper_evaluation_of_carcincogenic potential.pdf (accessed 24 Jan 2017).

40 Zoeller RT, Brown TR, Doan LL, et al. Endocrine-disrupting chemicals and public health protection: a statement of principles from the Endocrine Society. Endocrinology 2012;153:4097-110.

41 Mesnage R, Bernay B, Séralini GE. Ethoxylated adjuvants of glyphosate-based herbicides are active principles of human cell toxicity. Toxicology 2013:313:122-8

42 Tsui MT, Chu LM. Aquatic toxicity of glyphosate-based formulations: comparison between different organisms and the effects of environmental factors. Chemosphere 2003;52:1189-97.

43 Folmar LC, Sanders HO, Julin AM. Toxicity of the herbicide glyphosphate and several of its formulations to fish and aquatic invertebrates. Arch Environ Contam Toxicol 1979:8:269-78.

44 Defarge N, Takács E, Lozano VL, et al. Co-formulants in glyphosate-based herbicides disrupt aromatase activity in human cells below toxic levels. Int I Environ Res Public Health 2016;13

45 Guyton KZ, Loomis D, Grosse Y, et al. Carcinogenicity of tetrachlorvinphos, parathion, malathion, diazinon, and glyphosate. Lancet Onco 2015;16:490-1.

46 IARC. Glyphosate monograph. Some organophosphate insecticides and herbicides: diazinon, glyphosate, malathion, parathion, and tetrachlorvinphos. 2015. http://monographs.iarc.fr/ENG/Monographs/vol112/ mono112-09.pdf.

47 Greim H, Saltmiras D, Mostert V, et al. Evaluation of carcinogenic potential of the herbicide glyphosate, drawing on tumor incidence data from fourteen chronic/carcinogenicity rodent studies. Crit Rev Toxicol 2015;45: 185-208.

48 WHO. Frequently asked questions. In: JMPR secretariat, ed. 2016. http://www.who. int/foodsafety/faq/en/

49 IARC. Preamble: IARC monographs on the evaluation of carcinogenic risks to humans. Lyon, France: World Health Organization International Agency for Research on Cancer, 2006. 
50 BfR. Frequently asked questions on the assessment of the health risk of glyphosate. 2016. http://www.bfr.bund.de/en/frequently_asked_questions_on_the_assessment_ of_the_health_risk_of_glyphosate-127871.html

51 Beronius A, Hanberg A, Zilliacus J, et al. Bridging the gap between academic research and regulatory health risk assessment of endocrine disrupting chemicals. Curr Opin Pharmacol 2014;19:99-104.

52 Bergman A, Andersson AM, Becher G, et al. Science and policy on endocrine disrupters must not be mixed: a reply to a "common sense" intervention by toxicology journal editors. Environ Health 2013;12:69.
53 Trasande L, Vandenberg LN, Bourguignon JP, et al. Peer-reviewed and unbiased research, rather than 'sound science', should be used to evaluate endocrine-disrupting chemicals. J Epidemiol Community Health 2016;70:1051-6

54 European Commission. FAQs: Glyphosate. Secondary FAQs: Glyphosate, 2016.

55 Trasande L, Zoeller RT, Hass U, et al. Estimating burden and disease costs of exposure to endocrine-disrupting chemicals in the European Union. J Clin Endocrinol Metab 2015;100:1245-55. 